\title{
Atmospheric Dispersion of Gases and Odours from Animal Production Systems
}

\author{
Owen T. DenMead \\ (CSIRO Land and Water, GPO Box 1666, Canberra, ACT 2601, Australia)
}

\begin{abstract}
Animal production systems are major agricultural sources of the greenhouse gases, methane and nitrous oxide, of pollutants such as ammonia and hydrogen sulfide, and of odours. Verifying inventory estimates of their production, and monitoring, regulating and reducing their emission all require the ability to make precise, non-obtrusive measurements of their fluxes, and in the case of odours, an ability to predict concentrations close to the source. However, these requirements present special problems. The source areas are often small or irregularly shaped, the sources may be distributed heterogeneously, and emissions may be transient. Odours present an additional problem in that it is difficult to quantify their intensity since they are usually due to a mixture of more than 100 volatile organic compounds. The use of tracer gases to follow odour dispersion is discussed, but quantifying odour intensity is a pressing problem. The paper considers measurement techniques appropriate for sources of different shapes and sizes. Most attention is given to small and irregularly shaped sources for which conventional, large-area micrometeorological approaches are inapplicable: line-sources, strips, small plots, and waste storage areas such as ponds and manure piles. Mass balance techniques appear to be particularly useful for these purposes. Various applications of the methodology are considered in some detail. The advent of open-path gas lasers that can measure concentrations rapidly and over distances of hundreds of meters is seen as a significant development. Finally, the paper considers the use of a Lagrangian dispersion model that allows emissions from sources of any geometry to be linked to concentrations at any location downwind. In forward mode, it can predict downwind concentrations for given source scenarios, while in backward mode, it can infer fluxes from measurements of concentration and wind speed at just one height downwind. It is a very attractive tool for use in many dispersion problems relevant to the theme of the paper.
\end{abstract}

Key words: Pollutants, Tracers, Plane, Line and strip sources, Mass balance, Lagrangian dispersion

\section{Introduction}

Animal production systems are significant emitters of greenhouse gases, pollutants and odours. It is estimated that emissions of the greenhouse gas methane $\left(\mathrm{CH}_{4}\right)$ from enteric fermentation in ruminant animals and from animal wastes contribute some $30 \%$ of all anthropogenic emissions of this gas and that a similar figure applies to emissions of nitrous oxide $\left(\mathrm{N}_{2} \mathrm{O}\right)$ from grazing, feedlots and animal wastes; (Mosier et al., 1998a; 1998b; IPCC, 2001). Ammonia $\left(\mathrm{NH}_{3}\right)$ generated from animal wastes and emitted to the atmosphere has an important en-

Received on June 21, 2004.

Accepted on June 21, 2004. vironmental impact through its role in the formation of aerosols that affect the earth's radiation balance and cloud-forming processes, and through subsequent wet and dry deposition of $\mathrm{NH}_{3}$ and ammonium compounds that can cause soil acidification, eutrophication, and eventually the production and emission of $\mathrm{N}_{2} \mathrm{O}$ through nitrification and denitrification (Bouwman et al., 1997; Mosier et al., 1998c). Bouwman et al. (1997) estimate that global emissions of $\mathrm{NH}_{3}$ from animal production systems constitute $50 \%$ of all anthropogenic emissions of this gas. Further, the uncertainty levels associated with estimates of emissions of all three gases from animal production systems are high: about $\pm 30 \%$ for $\mathrm{CH}_{4}$, $\pm 70 \%$ for $\mathrm{N}_{2} \mathrm{O}$, and $\pm 50 \%$ for $\mathrm{NH}_{3}$ (Bouwman 
et al., 1997; Mosier et al., 1998a; 1998b; IPCC, 2001). Verifying and improving inventory estimates, reducing uncertainty, and evaluating proposed mitigation measures require precise, non-obtrusive measurement techniques.

The rapid development of intensive livestock production systems using confined rearing methods, often close to residential areas, is causing severe environmental problems through the creation of concentrated sources of malodorous animal wastes. The same problems arise again when the wastes are disposed of by application to agricultural fields. There are at least two needs: predicting concentrations for given source strengths, geometries and weather conditions, needed for planning and hazard assessment, and inferring source strengths from concentrations, needed for regulatory and control purposes.

Standard meteorological methods exist for predicting concentrations of gases and odours generated by large areal sources, and line and point sources, e.g., Pasquill and Smith (1983), Denmead (1994). These are examined briefly here. More serious problems are dispersion from small, irregularly-shaped sources, like lagoons, slurries, manure piles and barns, and dispersion from irregularly-spaced point sources such as grazing animals or the urine and dung patches they create. This overview is concerned particularly with micrometeorological techniques suitable for measuring emissions in such situations. The problem of predicting gas concentrations and odour intensities generated by such sources is addressed in the final section of this paper in discussion of a newly developed backward Lagrangian stochastic dispersion technique.

While most of the paper is concerned with measuring the strengths of small emitting sources, it sidesteps a very large problem in odour research: how to quantify odour intensity. Usually, olfactory response is subjective and is due to a mixture of compounds including ammonia $\left(\mathrm{NH}_{3}\right)$, hydrogen sulfide $\left(\mathrm{H}_{2} \mathrm{~S}\right)$ and $>100$ volatile organic compounds (Zahn et al., 2001). Olfactometry is used commonly to measure the concentration of odour in air through the use of a serial diluter, or an olfactometer, to present odourous air with odourless air dilutions to a panel of people, often in a specially prepared laboratory. Odour concentration is defined as the number of dilutions at which $50 \%$ of panel members can just detect an odour and is expressed in terms of Odour
Units $\mathrm{m}^{-3}$ (Hobbs et al., 1995). However, setting of air quality standards by regulatory authorities, prediction of odour dispersion and attempts to mitigate odour emissions all require objective measurements of odour intensity. Much work is now under way on this topic, e.g., the development of photoionization detectors, electronic noses, and gas chromatographymass spectrometry systems (Hobbs et al., 1995). For simplicity, we assume in this paper that odour concentrations can be measured directly or estimated from concentrations of some tracer gas dispersing with the odour.

\section{Use of Tracers}

Here, we consider the problem of inferring source strengths from concentration measurements. For the greenhouse gases and pollutants like $\mathrm{NH}_{3}$ and $\mathrm{H}_{2} \mathrm{~S}$, or if odours can be identified and measured on-line, the methods outlined in following sections can be applied directly. It will often be the case, however, that concentrations are very small and/or difficult to measure on-line and we need to rely on a ratio technique. The source strength of a tracer gas dispersing with the substance in question, that has the same spatial source distribution and time dependence, is measured and the flux of the substance is calculated from the product of the tracer gas flux and the ratio of the concentration of the substance to that of the tracer at the same separation from the source. $\mathrm{NH}_{3}$ and $\mathrm{H}_{2} \mathrm{~S}$ are possible tracers. Others might be carbon dioxide $\left(\mathrm{CO}_{2}\right), \mathrm{CH}_{4}$ and $\mathrm{N}_{2} \mathrm{O}$. It can be shown that downwind of a change in surface flux, the change in concentration of the emitted substance from its upwind concentration is directly proportional to the downwind flux. Assuming that the dispersing substance and the tracer are subject to the same atmospheric transport mechanisms and that both are non-reactive,

$$
F_{\mathrm{s}}=\left(\delta \rho_{\mathrm{s}} / \delta \rho_{\mathrm{t}}\right) F_{\mathrm{t}}
$$

where $F_{\mathrm{s}}$ and $F_{\mathrm{t}}$ are the fluxes of substance and tracer, respectively, and $\delta \rho_{\mathrm{s}}$ and $\delta \rho_{\mathrm{t}}$ are the corresponding concentration changes. Figure 1 (from a landfill study described by Denmead et al., 1998) provides confirmation of this. Figure 1a shows changes in the concentrations of methane $\mathrm{CH}_{4}$ and carbon dioxide $\mathrm{CO}_{2}$ at a height of $0.5 \mathrm{~m}$ over a distance of $100 \mathrm{~m}$ downwind of the leading edge of a landfill. The slope of the line (1.03) is the ratio of 

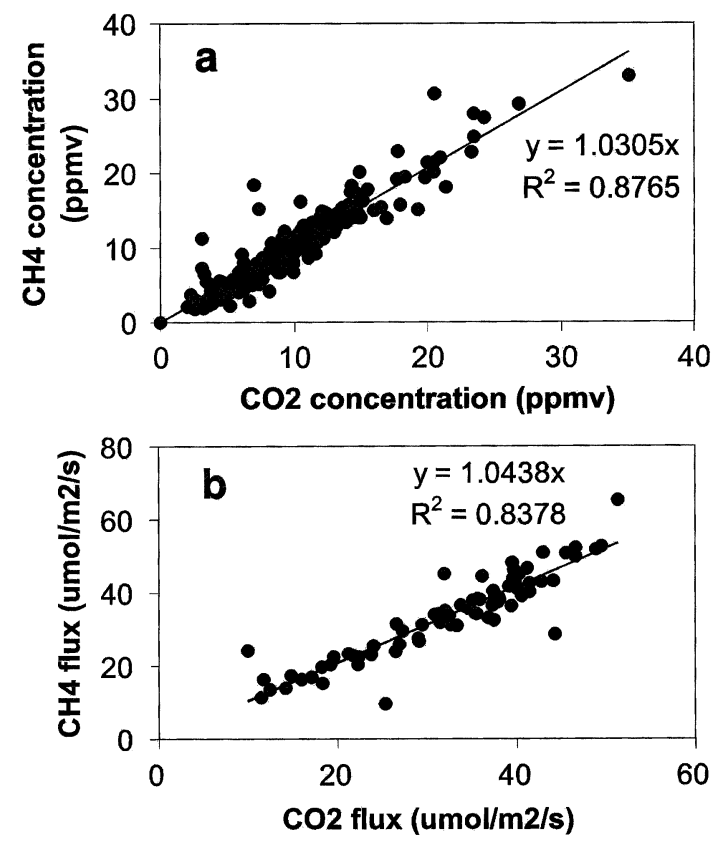

Fig. 1. (a) Enrichment in the concentrations of methane and carbon dioxide, measured at $0.5 \mathrm{~m}$ above ground, over a downwind distance of 100 $\mathrm{m}$, in a landfill. (b) Simultaneous fluxes of $\mathrm{CH}_{4}$ and $\mathrm{CO}_{2}$ from surface of the landfill, after Denmead et al. (1998).

the two $\delta$ s. Figure $1 \mathrm{~b}$ shows the corresponding fluxes of the two gases. The slope of the line (1.04) is virtually the same as the ratio of the $\delta$ s, confirming the validity of Eq. (1).

A similar argument can be made for the build-up in gas concentrations that occurs in calm, stablystratified, near-surface air at night, i.e., in the nocturnal boundary layer (NBL). The emission rate of the target gas or odour can be inferred from the ratio of the simultaneous rate of increase of its concentration, measured at a convenient level in the NBL, to that of a tracer gas with a similar surface source distribution, whose rate of emission is known. Kelliher et al. (2002) used this approach to calculate emission rates of $\mathrm{N}_{2} \mathrm{O}$ from grazed pastures. They used $\mathrm{CO}_{2}$ as the tracer gas. The NBL approach has much promise for linking gas or odour concentrations and their respective source strengths. Concentrations in the NBL will be much higher than by day, hence easier to measure, and there are several likely tracer gases whose rates of emission can be measured with currently available technologies, e.g. $\mathrm{CO}_{2}, \mathrm{NH}_{3}$,
$\mathrm{H}_{2} \mathrm{~S}, \mathrm{CH}_{4}$ and $\mathrm{N}_{2} \mathrm{O}$ itself.

\section{Emissions from Large Plane Areas}

\subsection{Semi-infinite plane source}

For a large flat uniform source, such as a field where manure has been spread, standard micrometeorological flux measurement techniques can be used. The flux of gas from the surface can be calculated from energy balance, aerodynamic, eddy correlation, or eddy accumulation approaches. Those techniques are well known and need no explanation here. If, however, the gas is emitted directly from animal sources, like $\mathrm{CH}_{4}$ from grazing ruminants, or $\mathrm{N}_{2} \mathrm{O}$ and $\mathrm{NH}_{3}$ from the urine patches created by the animals, special precautions need to be taken to ensure uniformity in source distributions. For instance, in a study of $\mathrm{CH}_{4}$ emissions from grazing sheep, Judd et al. (1999) employed a high stocking rate of 20 sheep ha ${ }^{-1}$ over a grazed area of $12 \mathrm{ha}$ and arranged fencing so that the sheeppopulated pasture extended hundreds of meters both upwind and laterally.

\subsection{Semi-infinite line source or semi-infinite strip}

Often, emissions from volatile wastes spread on the ground are short-lived and the problem is to define the time-course of the emission. Then, it may be more convenient to work with a smaller emitting area created by one or a few runs of an applicator than to wait for hectare sized areas to be created. In this case, we will be seeking solutions of the 2dimensional atmospheric diffusion equation:

$$
u \frac{\partial \rho}{\partial x}=\frac{\partial}{\partial z}\left(K \frac{\partial \rho}{\partial z}\right)
$$

where $u$ denotes wind speed, $\rho$ concentration, $x$ horizontal distance downwind, $z$ height and $K$ the eddy diffusivity for the gas in question. When, as is usually the case, the wind profile is logarithmic and $K$ linear with height, it is difficult to obtain exact mathematical solutions for Eq. (2) and numerical techniques are often employed. However, the use of power law profiles for the height dependence of $u$ and $K$ leads to analytical solutions. The power-law profiles have the form:

$$
u=u_{1}\left(z / z_{1}\right)^{m},
$$

and

$$
K=K_{1}\left(z / z_{1}\right)^{n},
$$


where $u_{1}$ and $K_{1}$ are the values of $u$ and $K$ at a reference height $z_{1}$, and $m$ and $n$ are constants whose values depend on surface roughness and atmospheric stability. Often, conjugate power laws, for which $n=1-m$, are employed. Sutton (1953) has presented a solution for the problem of atmospheric dispersion from semi-infinite, cross-wind line sources. This links concentrations and source strengths:

$$
\begin{aligned}
\rho(x, z)= & \frac{Q}{u_{1} \Gamma(a)}\left\{\frac{u_{1}}{(2 m+1)^{2} K_{1} x}\right\}^{a} \\
& \times \exp \left\{-\frac{u_{1} z^{2 m+1}}{(2 m+1)^{2} K_{1} x}\right\},
\end{aligned}
$$

where $\rho$ is concentration in excess of background, $x$ is distance downwind from the source, $z$ is the height of measurement, $Q$ is the source strength, $a=(m+$ $1) /(2 m+1)$, and $\Gamma$ denotes the gamma function. Philip (1959) has presented similar solutions for a semi-infinite strip. For a boundary condition of a constant concentration at the surface, the solution has the form:

$$
\begin{aligned}
\rho(x, z)= & \bar{F}(1-I(\eta, a)) \\
& / \frac{1+2 m}{\Gamma\left(\frac{m}{1+2 m}\right)} \cdot \frac{(1+2 m)^{2} K_{1}}{u_{1}} \cdot \frac{x^{-m /(1+2 m)}}{a},
\end{aligned}
$$

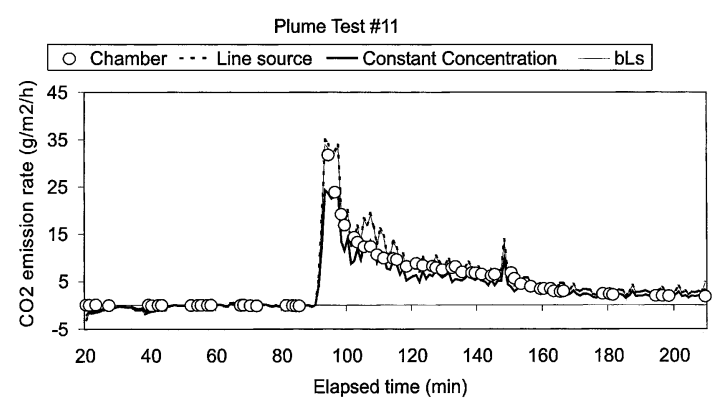

Fig. 2. Comparison of emissions of $\mathrm{CO}_{2}$ from a tilled strip, calculated by 3 micrometeorological methods, with chamber measurements, before and immediately after tillage (at approximately $90 \mathrm{~min}$ ), from Denmead and Reicosky (2003). The calculations were made using solutions for a cross-wind line source (Sutton, 1953), a cross-wind plane source with a constant concentration at the surface (Philip, 1959), and a backward Lagrangian stochastic (BLS) dispersion analysis (Flesch et al., 1995). where $\bar{F}$ is the average surface flux from the strip, $I$ is the incomplete gamma function, and the other symbols are as before.

Denmead and Reicosky (2003) used both solutions to calculate fluxes of $\mathrm{CO}_{2}$ from soil after tillage. Measurements of $\mathrm{CO}_{2}$ concentration were made at $0.2 \mathrm{~m}$ above the surface on the upwind and downwind edges of a ploughed strip $50 \mathrm{~m}$ long and $5.6 \mathrm{~m}$ wide, comprising 12 furrows. Combined with measurements of wind direction and wind speed at the same height, these led to line-source solutions for source strength for each of the furrows, through inverting Eq. (5). The average $Q$ was obtained by noting that the concentration $C$ measured at $0.2 \mathrm{~m}$ was the sum of the concentrations generated by each of the furrows. The mean flux per unit area in the treated zone $\bar{F}$ was given by $\bar{F}=Q / w, w$ being the width between furrows. Fluxes calculated in this way and those calculated through Philip's solution for a semi-infinite strip are compared with $\mathrm{CO}_{2}$ fluxes measured simultaneously on the strip with a dynamic, closed chamber, in Fig. 2. The agreement between the calculated and measured fluxes is excellent for both approaches and suggests that strip applications could be a relatively easy way to measure gaseous emissions from animal wastes disposed in the field through spreading or incorporation. In this case, $\mathrm{NH}_{3}$ or $\mathrm{H}_{2} \mathrm{~S}$ could be useful tracers of odours.

Section 5 of the paper describes a backward Lagrangian dispersion (BLS) technique that allows inference of source strength from concentrations measured at a known distance and height downwind. Fluxes calculated by this method are also shown in Fig. 2. Like the power-law solutions, these are in very good agreement with the chamber observations. The BLS approach also appears to be a very simple and convenient way to analyse line-source and strip emission problems.

\section{Emissions from Small Surface Sources}

These are the sources of most concern and they can be the most difficult to handle because they may require 3-dimensional solutions. They include small plots, feedlots, effluent lagoons, slurry tanks and manure piles, and scattered point sources such as animals and the dung and urine patches they create. At distances far enough from the source, they can be treated as point sources and their dispersion analysed by classical diffusion methods. Usually, however, the 
concern is with concentrations close to the source, where conventional micrometeorological methods for linking concentrations and source strengths don't apply. Problems of this kind have engendered much innovation in the last few years, notably through the development of mass balance techniques and Lagrangian descriptions of atmospheric dispersion.

\subsection{Mass balance techniques}

\subsubsection{Integrated horizontal flux}

Developed originally for inferring trace gas fluxes from small regularly-shaped agronomist's plots, mass balance methods of varying complexity can be applied to virtually any geometry, e.g., Wilson et al. (1982), Denmead et al. (1998). Their basis is simple, depending only on the conservation of mass. The simplest situation to consider is a 2-dimensional one where the fetch $X$ is fixed or calculable. Then, the net horizontal flux across the downwind edge of the emitting area can be equated with the surface flux within it, so that

$$
\bar{F}=(1 / X) \int_{0}^{Z} \bar{U}\left(\overline{\rho_{x}}-\overline{\rho_{0}}\right) \mathrm{d} z
$$

where $\bar{F}$ denotes the average flux density within the area, $\rho_{x}$ and $\rho_{0}$ are the gas concentrations on the downwind and upwind boundaries, and $Z$ is the height of the air layer affected by the emission. This approach, dubbed the integrated horizontal flux (IHF) technique by Wilson et al. (1982), is independent of atmospheric stability and requires no particular form for the wind profile. It has been used in many contexts relevant to the theme of this paper, e.g., by Ryden and McNeill (1984) to determine $\mathrm{NH}_{3}$ loss from a pasture grazed by cattle, by Khan et al. (1997) to measure $\mathrm{CH}_{4}$ emissions from stored cattle slurry and by Brown et al. (2002) to measure emissions of $\mathrm{N}_{2} \mathrm{O}$ from a manure pile. It should be noted that Eq. (7) is written in terms of time means of wind speed and gas concentration. However, as discussed by Denmead et al. (1998), the equation describes only the apparent convective horizontal flux and neglects the turbulent diffusive flux in the upwind direction with the result that it overestimates the true horizontal flux. To account for this, Denmead et al. (1998) suggest that fluxes calculated by Eq. (7) should be reduced by a small amount which, on empirical evidence, they set at $15 \%$. Desjardins et al. (2004) suggest a correction of 5\%, Ryden and McNeill (1984) 10\%, and Wilson and
Shum (1992) up to $20 \%$.

\subsubsection{Theoretical profile shape and circular plots}

Simplifications of the technique stem from the demonstration by Wilson et al. (1982) that for a given fetch and surface roughness, there is one particular height where the stable, neutral and unstable horizontal flux profiles intersect. Horizontal fluxes measured at that height are always in the same ratio to $\bar{F}$, regardless of atmospheric stability, so that measurements of $\bar{U}$ and $\bar{\rho}$ at only that height are all that is necessary to calculate $\bar{F}$. Wilson et al. (1982) call that stability-independent height ZINST. In order to keep the fetch, hence ZINST, constant, experimental plots should be circular with $\bar{U}$ and $\bar{\rho}$ measured at the plot centre. Wilson et al. (1982) provide nomograms, for different plot radii and surface roughness, for deducing both ZINST and the ratio of the horizontal flux there to $\bar{F}$. The same parameters for other-sized plots are provided by Wilson et al. (1983) and Denmead (1983). The approach via ZINST is labelled the theoretical profile shape (TPS) method. Pain et al. (1989) used the method to measure emissions of $\mathrm{NH}_{3}$ from slurries spread on the ground and Pain et al. (1991) describe an application of the technique in which odour emissions were calculated from measurements of $U$ and odour intensity (assessed by a panel) at ZINST.

\subsubsection{Three-dimensional mass balance approaches}

Denmead et al. (1998) describe a more elaborate, 3-dimensional mass balance approach in which vertical profiles of gas concentration are measured on $\mathrm{N}$, $\mathrm{S}, \mathrm{E}$ and $\mathrm{W}$ boundaries of a square of side $X$ around the emitting area. When multiplied by the profile of wind speed, these yield profiles of the horizontal flux of the gas across each boundary. The difference between the integrated horizontal fluxes on downwind and upwind boundaries represents production in the emitting area. If we denote the rate of production by $F_{0}$, the vector wind speeds by $U(\mathrm{~N}-\mathrm{S})$ and $V(\mathrm{~W}-\mathrm{E})$ and gas densities by $\rho$, then

$$
\begin{aligned}
\bar{F}_{0}= & X \int_{0}^{Z}\left[\bar{U}\left(\left\langle\overline{\rho_{\mathrm{S}, z}}\right\rangle-\left\langle\overline{\rho_{\mathrm{N}, z}}\right\rangle\right)\right. \\
& \left.+\bar{V}\left(\left\langle\overline{\rho_{\mathrm{E}, z}}\right\rangle-\left\langle\overline{\rho_{\mathrm{W}, z}}\right\rangle\right)\right] \mathrm{d} z
\end{aligned}
$$

In Eq. (8), $U=u \cos \alpha$ and $V=u \sin \alpha, u$ being the total wind speed at height $z$ and $\alpha$ the wind direction measured clockwise from $\mathrm{N}, Z$ is the height of the layer affected by the emission and is of order $0.1 X$, the overbars denote time means and the angular 

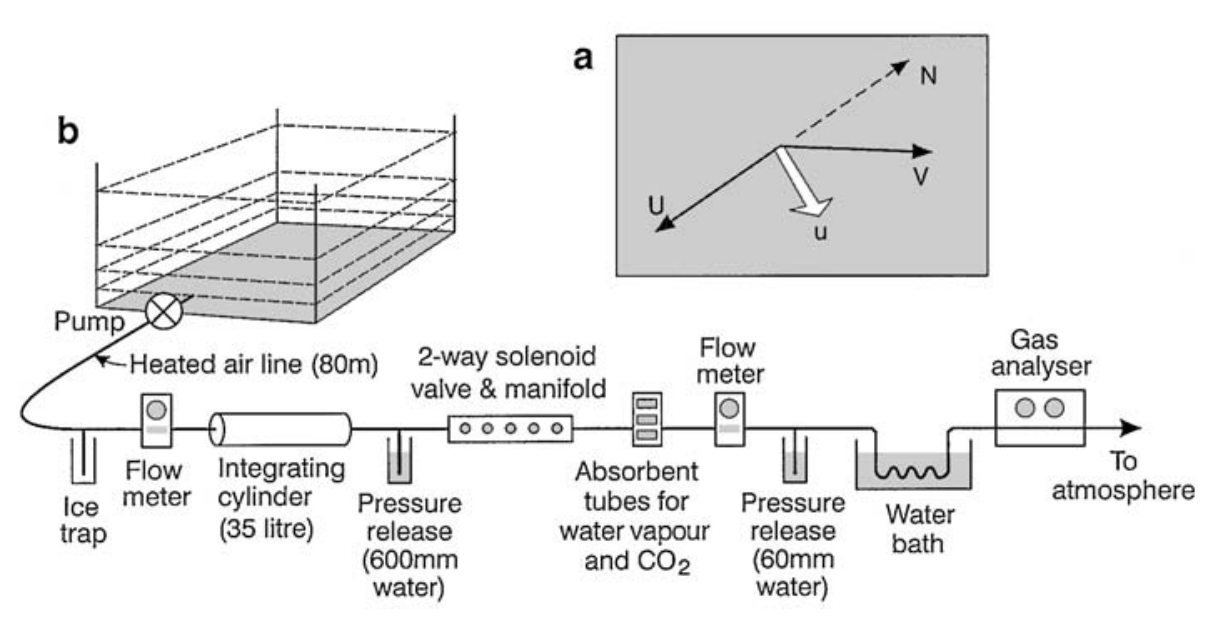

Fig. 3. Schematic of experimental test plot and gas sampling system used by Leuning et al. (1998) and Harper et al. (1999) to measure methane emissions from grazing animals. In this case, side length $X$ was $22 \mathrm{~m}$ and gas intakes, the dashed lines in (b), were at heights of $0.5,1,2$ and $3.5 \mathrm{~m} . u$ denotes total wind speed, $U$ is the wind speed normal to $\mathrm{N}$ and $\mathrm{S}$ boundaries and $V$ that normal to the $\mathrm{E}$ and $\mathrm{W}$ boundaries. From Denmead et al. (1998).

brackets spatial means. Harper et al. (1999) and Leuning et al. (1998) have used the technique to measure $\mathrm{CH}_{4}$ production by cattle and sheep in small fields, $22 \mathrm{~m} \times 22 \mathrm{~m}$. Figure 3 is an illustration of the system employed in both studies. Sampling tubes, of $25 \mathrm{~mm}$ diameter, were mounted at 4 heights on each boundary and completely surrounded the test area. Air was drawn into each of the tubes through $20 \mathrm{~mm}$ lengths of capillary tube, of diameter $0.3 \mathrm{~mm}$, sealed into the larger tubes at $1 \mathrm{~m}$ intervals. Each sampling tube was connected to a pump delivering air at $4 \mathrm{~L} /$ min to a buffer volume which was connected via a manifold to a gas analyzer in the manner shown in the figure.

\subsubsection{Modified mass balance approach for open- path sensors}

The advent of open-path lasers and Fourier Transform Infrared (FTIR) Spectrometers that can measure spatially averaged concentrations of candidate gases such as $\mathrm{NH}_{3}, \mathrm{H}_{2} \mathrm{~S}, \mathrm{CO}_{2}, \mathrm{CH}_{4}$ and $\mathrm{N}_{2} \mathrm{O}$ over distances of hundreds of meters promises to extend the usefulness of mass balance approaches considerably. Because of the long measuring path of these instruments, the problem can be reduced to measuring concentrations on only the upwind and downwind boundaries. As well, concentration measurements can be made rapidly, so that when the lasers are coupled with measurements of wind speed and direction by 2-dimensional sonic anemometers, fluxes can be calculated almost instantaneously. This overcomes problems of varying fetch and source location and the need to apply corrections to flux estimates obtained from the time-means of wind speeds and concentrations (Section 4.1.1). An evaluation of the potential utility of the modified technique has been given recently by Desjardins et al. (2004). They concluded that with sufficient replication, the technique could detect a change in emission rate of $9 \%$ and that attention to perceived weaknesses should improve the resolution to close to $5 \%$. The modified approach should be particularly useful for measuring gas emissions from herds, lagoons, manure piles and buildings.

\section{Lagrangian Dispersion}

Flesch et al. (1995) describe a backward-time Lagrangian stochastic dispersion model (the BLS model) that calculates trajectories of air parcels backward in time from a sensor location to a specified source. It uses a large number of simulated releases to calculate the probability that parcels departing from the sensor will touch down within the source area thus permitting calculation of the contribution of the source to the concentration and the horizontal flux of the emitted gas at the sensor. The working of the model is illustrated in Fig. 4. The 


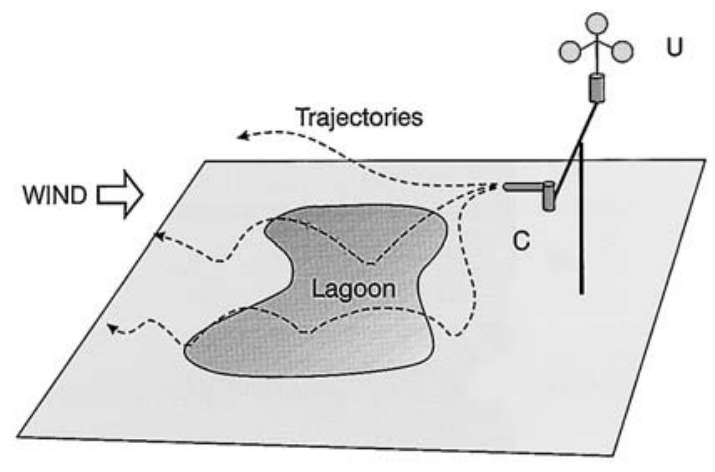

Fig. 4. Schematic of the application of the BLS analysis to dispersion of gas from a lagoon. Trajectories of air parcels are traced backward in time from the gas sensor, and the touchdowns in the source area (the lagoon) and outside it are counted. This allows calculations of the contributions of each area to the concentration measured by the sensor, hence the contribution to the horizontal flux there.

input requirements are source geometry, surface roughness, atmospheric stability and the height and distance downwind of the sensor. The output is the ratio of the horizontal flux at the sensor to the mean emission rate within the source area. This allows emissions from sources of any geometry to be linked to concentrations at any location downwind. Thus, the model can be used for both measurement of source strengths and prediction of concentrations.

The usefulness of the method for measuring emissions from line-sources and strips was demonstrated in Fig. 2. Figure 5 (from unpublished work of O.T. Denmead, D. Chen and J. R. Freney, 1998) provides evidence of the success of the model for calculating emissions from larger plane sources. In this instance, a conventional micrometeorological approach and both the BLS and the TPS methods were used to estimate $\mathrm{NH}_{3}$ emissions from a fertilized field. The fertilized area was a circle of $95 \mathrm{~m}$ radius, with an area of 2.84 ha. Measurements of wind speed, $\mathrm{NH}_{3}$ concentration and atmospheric stability were made on a tower at the centre of the circle. $\mathrm{NH}_{3}$ emission rates were calculated by an aerodynamic fluxgradient technique using concentration measurements at 0.26 and $1.1 \mathrm{~m}$, by the BLS method from measurements at only $1.1 \mathrm{~m}$, and by the TPS method from measurements at the ZINST of $2.9 \mathrm{~m}$. Figure 5a compares surface fluxes calculated by the aero-
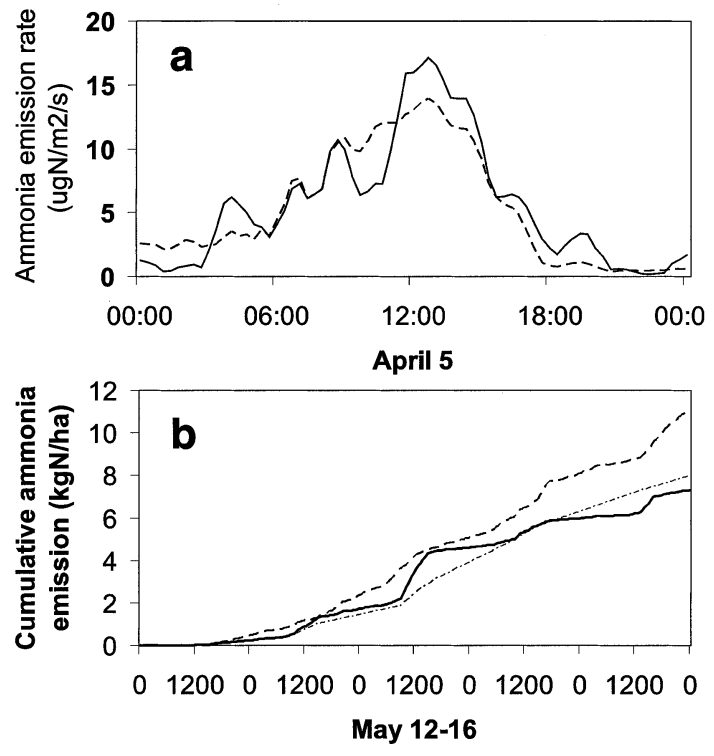

Fig. 5. (a) Ammonia emission from a circular pasture plot of $95 \mathrm{~m}$ radius after fertilization with urea. Solid line for emissions calculated from an aerodynamic technique using measurements of wind speed, temperature, and ammonia concentration at heights of 0.26 and $1.1 \mathrm{~m}$ at the centre of the plot; dashed line for the BLS method using the measurements at $1.1 \mathrm{~m}$. (b) Cumulative emissions over 5 days calculated by the aerodynamic technique (heavy dashed line), the BLS method (solid line), and the TPS method using measurements of wind speed and $\mathrm{NH}_{3}$ concentration at the ZINST of $2.9 \mathrm{~m}$ (light dashed line). (From unpublished work of O.T. Denmead, D. Chen and J. R. Freney, 1998.)

dynamic and BLS methods over a $24 \mathrm{~h}$ period, and Fig. $5 \mathrm{~b}$ compares the cumulative fluxes measured by the 3 approaches. In both instances, the simplified 1level measurement techniques provided very good agreement with the more complicated 2-level fluxgradient approach. Though not quite as simple in application as the TPS method since knowledge of atmospheric stability is required, the BLS model ${ }^{1}$ is a very valuable tool for investigating dispersion from source areas of any shape, and it has the ability to operate in both forward and inverse modes, i.e. to

\footnotetext{
${ }^{1}$ The BLS model is incorporated in a commercial package, WindTrax (available from Thunder Beach Scientific, 4B-1127 Cartaret Street, Halifax, Nova Scotia, Canada B3H 3P2), that greatly facilitates its application.
} 


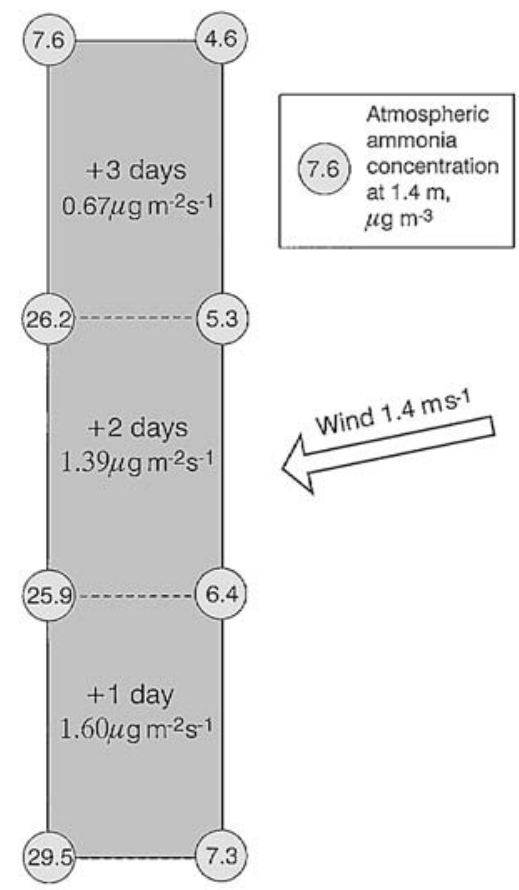

Fig. 6. Application of the BLS method to calculating emissions of ammonia from a pasture that had been grazed by 315 dairy cows. The pasture was grazed in rotation over 3 days. Each grazed section was $65 \mathrm{~m}$ wide and $122 \mathrm{~m}$ long. Atmospheric $\mathrm{NH}_{3}$ concentrations (encircled) were measured at a height of $1.4 \mathrm{~m}$ at 8 points on the boundary of the pasture. The fluxes of $\mathrm{NH}_{3}$ from each of the grazed sections were calculated by the BLS method from the concentration measurements and those of wind speed at $1.4 \mathrm{~m}$ and wind direction (arrow). Fluxes and the time since grazing are shown for each section in the body of the figure. (From unpublished work of O.T. Denmead, D. Turner and D. Chen, 2004.)

predict both concentrations and fluxes.

A further example of the versatility of the BLS model is provided by Fig. 6 (from an unpublished study of $\mathrm{NH}_{3}$ emissions from grazed pastures by $\mathrm{O}$. T. Denmead, D. Turner and D. Chen, 2004). The figure shows simultaneous $\mathrm{NH}_{3}$ emissions calculated by the model for different, adjoining sections of a field, each $65 \mathrm{~m}$ wide and $122 \mathrm{~m}$ long. The sections had been grazed in rotation on 3 successive days by a herd of dairy cattle. The numbers in the body of the figure indicate the number of days since each section was grazed and the surface flux from it, and the numbers on the boundaries indicate atmospheric $\mathrm{NH}_{3}$ concentrations measured at a height of $1.4 \mathrm{~m}$ above the ground. The wind direction and speed at $1.4 \mathrm{~m}$ are also indicated in the figure. Obtaining such detail would be difficult with any other technique.

\section{References}

Bouwman, A.F., Lee, D. S., Asman, W.A.H., Dentener, F. J., Van Der Hoek, K.W. and Olivier, J. G. J., 1997: A global high-resolution emission inventory for ammonia. Global Biogeochem. Cycles, 11, 561-587.

Brown, H. A., Wagner-Riddle, C. and Thurtell, G. W., 2002: Nitrous oxide flux from a solid dairy manure pile measured using a micrometeorological mass balance method. Nutr. Cycling Agroecosys., 62, 53-60.

Denmead, O.T., 1983: Micrometeorological methods for measuring gaseous losses of nitrogen in the field. In Gaseous loss of nitrogen from plant-soil systems (ed. by Freney, J. R. and Simpson, J. R.). Martinus Nijhoff/Dr W. Junk, The Hague, pp. 133-157.

Denmead, O. T., 1994: Measuring fluxes of $\mathrm{CH}_{4}$ and $\mathrm{N}_{2} \mathrm{O}$ between agricultural systems and the atmosphere. In $\mathrm{CH}_{4}$ and $\mathrm{N}_{2} \mathrm{O}$. Global emissions and controls from rice fields and other agricultural and industrial sources (ed. by Minami, K., Mosier, A. and Sass, R.). National Institute of AgroEnvironmental Sciences, Tsukuba, pp. 209-234.

Denmead, O. T. and Reicosky, D. C., 2003: Tillageinduced gas fluxes: comparison of meteorological and large chamber techniques. Proc. ISTRO 16, Int. Soil Tillage Research Organisation 16th Triennial Conference, Brisbane, 2003, pp. 357-363.

Denmead, O.T., Harper, L.A., Freney, J. R., Griffith, D. W. T., Leuning, R. and Sharpe, R. R., 1998: A mass balance method for non-intrusive measurements of surface-air trace gas exchange. Atmos. Environ., 32, 3679-3688.

Desjardins, R., Denmead, O.T., Harper, L.A., McBain, M., Masse, D. and Kaharabata, S., 2004: Evaluation of a micrometeorological mass balance method employing open-path lasers for measuring methane emissions. Atmos. Environ. (in press).

Flesch, T.K., Wilson, J.D. and Yee, E., 1995: Backward-time Lagrangian stochastic dispersion models and their application to estimate gaseous emissions. J. Appl. Meteorol., 34, 1320-1332.

Harper, L. A., Denmead, O.T., Freney, J.R. and Byers, F. M., 1999: Direct measurements of methane emissions from grazing and feedlot cattle. $J$. Animal Sci., 77, 1392-1401.

Hobbs, P.J., Misselbrook, T.H. and Pain, B.F., 
1995: Assessment of odours from livestock wastes by photoionization detector, an electronic nose, olfactometry and gas chromatography-mass spectrometry. J. Agric. Eng. Res., 60, 137-144.

IPCC, 2001. Climate change 2001: The scientific basis. Contribution of working group 1 to the third assessment report of the intergovernmental panel on climate change (ed. by Houghton, J. T., Ding, Y., Griggs, D. J., Noguer, M., van der Linden, D. J., Dai, X., Maskell, K. and Johnson, C. A.). Cambridge University Press, Cambridge, pp. 239-287.

Judd, M. J., Kelliher, F. M., Ulyatt, M. J., Lassey, K. R., Tate, K. R., Shelton, I. D., Harvey, M. D. and Walker, C.F., 1999: Net methane emissions from grazing sheep. Global Change Biol., 5, 647657.

Kelliher, F.M., Reisinger, A. R., Martin, R. J., Harvey, M. J., Price, S. J. and Sherlock, R. R., 2002: Measuring nitrous oxide emission rate from grazed pasture using Fourier-transform infrared spectroscopy in the nocturnal boundary layer. Agric. For. Meteorol., 111, 29-38.

Khan, R.Z., Muller, C. and Sommer, S. G., 1997 : Micrometeorological mass balance technique for measuring $\mathrm{CH}_{4}$ emission from stored cattle slurry. Biol. Fertil. Soils, 24, 442-444.

Leuning, R., Baker, S. K., Jamie, I. M., Hsu, C. H., Klein, L., Denmead, O. T. and Griffith, D. W. T., 1998: Methane emission from free-ranging sheep: a comparison of two measurement techniques. Atmos. Environ., 33, 1357-1365.

Mosier, A. R., Duxbury, J. M., Freney, J. R., Heinemeyer, O., Minami, K. and Johnson, D. E., 1998a: Mitigating agricultural emissions of methane. Climatic Change, 40, 39-80.

Mosier, A. R., Duxbury, J. M., Freney, J. R., Heinemeyer, O. and Minami, K., 1998b: Assessing and mitigating $\mathrm{N}_{2} \mathrm{O}$ emissions from agricultural soils. Climatic Change, 40, 7-38.

Mosier, A., Kroeze, C., Nevison, C., Oenema, O., Seitzinger, S. and van Cleemput, O., 1998c: Closing the global $\mathrm{N}_{2} \mathrm{O}$ budget: nitrous oxide emissions through the agricultural nitrogen cycle.
Nutr. Cycling Agroecosys., 52, 225-248.

Pain, B.F., Phillips, V.R., Clarkson, C.R. and Klarenbeek, J. V., 1989: Loss of nitrogen through ammonia volatilization during and following the application of pig or cattle slurry to grassland. $J$. Sci. Food Agric., 47, 1-12.

Pain, B.F., Clarkson, C. R., Phillips, V.R., Klarenbeek, J. V., Misselbrook, T.H. and Bruins, M., 1991: Odour emission arising from application of livestock slurries on land: Measurements following spreading using a micrometeorological technique and olfactometry. J. Agric. Eng. Res., 48, 101-110.

Pasquill, F. and Smith, F. B., 1983: Atmospheric diffusion, 3rd ed., John Wiley, New York.

Philip, J. R., 1959: The theory of local advection: I. J. Meteorol., 16, 535-547.

Ryden, J. C. and McNeill, J. E., 1984: Application of the micrometeorological mass balance method to the determination of ammonia loss from a grazed sward. J. Sci. Food Agric., 35, 1297-1310.

Sutton, O. G., 1953: Micrometeorology, McGrawHill, London, 333 pp.

Wilson, J.D. and Shum, W.K.N., 1992: A reexamination of the integrated horizontal flux method for estimating volatilization from circular plots. Agric. For. Meteorol., 57, 281-295.

Wilson, J.D., Catchpoole, V.R., Denmead, O. T. and Thurtell, G. W., 1983: Verification of a simple micrometeorological method for estimating the rate of gaseous mass transfer from the ground to the atmosphere. Agric. Meteorol., 29, 183-189.

Wilson, J.D., Thurtell, G.W., Kidd, G.E. and Beauchamp, E. G., 1982: Estimation of the rate of gaseous mass transfer from a surface plot to the atmosphere. Atmos. Environ., 16, 1861-1867.

Zahn, J. A., DiSpirito, A. A., Do, Y.S., Brooks, B. E., Cooper, E. E. and Hatfield, J. L., 2001 : Correlation of human olfactory responses to airborne concentrations of malodorous volatile organic compounds emitted from swine effluent. J. Environ. Qual., 30, 624-634. 